\title{
Estudo da ocorrência de internações por Asma via variáveis climáticas na Região Norte (PA)
}

Este trabalho teve por objetivo captar associações significativas entre internações e variáveis meteorológicas em municípios localizados na Região Norte do Brasil. As cidades utilizadas foram Altamira, Belém, Conceição do Araguaia, Itaituba, Marabá e Óbidos. Trabalhou-se com dados mensais de precipitação pluviométrica, umidade relativa do ar, temperatura máxima e temperatura mínima, disponibilizados pelo Banco de Dados Meteorológicos para Ensino e Pesquisa (BDMEP) e registros de internações por asma, segundo o local de residência, do Banco de Dados do Sistema Único de Saúde (DATASUS) do Ministério da Saúde. Levando-se em conta as características específicas dos dados em estudo, utilizaram-se as equações de estimação generalizadas. Em todas as cidades, o modelo estatístico constatou associações significativas diretas e/ou inversas entre as variáveis e as internações, mostrando que provavelmente o aumento ou diminuição nos números de casos de internações por asma, no período de 2000 a 2016; pode-se também levar em conta fatores climáticos. É de suma importância evidenciar que as questões climáticas também são um dos muitos agentes causadores de internações por asma. Os diagnósticos por uso de medicações e outros fatores, não foram avaliados neste trabalho. Espera-se que os resultados encontrados, possam contribuir para o planejamento de políticas públicas de saúde e meio ambiente.

\section{Study of the occurrence of asthma hospitalizations via climatic variables in the Northern Region (PA)}

\begin{abstract}
This study aimed to capture significant associations between hospitalizations and meteorological variables in municipalities located in the northern region of Brazil. The cities used were Altamira, Belem, Conceição do Araguaia, Itaituba, Marabá and Óbidos. Monthly data on rainfall, relative humidity, maximum temperature and minimum temperature, provided by the Meteorological Data Bank for Teaching and Research (BDMEP) and records of hospitalizations for asthma, according to place of residence, of the Banco de Data from the Unified Health System (DATASUS) of the Ministry of Health. Considering the specific characteristics of the data under study, generalized estimation equations were used. In all cities, the statistical model found significant direct and / or inverse associations between variables and hospitalizations, showing that probably the increase or decrease in the number of cases of hospitalizations for asthma between 2000 and 2016; climate factors can also be considered. It is extremely important to highlight that climate issues are also one of the many causative agents of hospitalizations for asthma. Diagnoses by medication use and other factors were not evaluated in this study. It is hoped that the results found may contribute to the planning of public health and environment policies.
\end{abstract}

Keywords: Asthma; Associations; Climate; North, Health.

Topic: Epidemiologia e Saúde Ambiental

Reviewed anonymously in the process of blind peer.
Received: $14 / 08 / 2018$

Approved: 19/08/2018
Vivianne Martins de Alfaia

Universidade Federal do Oeste Pará, Brasil http://lattes.cnpq.br/9961324624092308 alfaiavivimartins@gmail.com

\section{Ana Carla dos Santos Gomes (iD)}

Universidade Federal do Oeste do Pará, Brasil

http://lattes.cnpq.br/7570030284513470

http://orcid.org/0000-0001-7499-8342

anacarlag02@gmail.com

Tiago Bentes Mandú

Universidade Federal do Oeste do Pará, Brasi

http://lattes.cnpq.br/9653045843814574

tiagobentes1@gmail.com

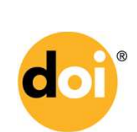

DOI: 10.6008/CBPC2179-6858.2018.006.0016

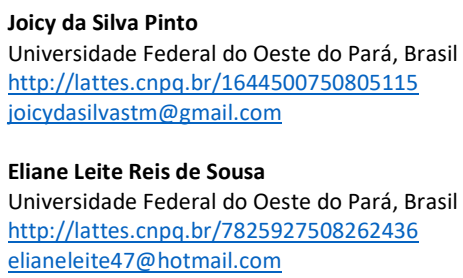

\section{Referencing this:}

ALFAIA, V. M.; GOMES, A. C. S.; MANDÚ, T. B.; PINTO, J. S.; SOUSA, E. L. R.. Estudo da ocorrência de internações por Asma via variáveis climáticas na Região Norte (PA). Revista Ibero Americana de Ciências Ambientais, v.9, n.6, p.147-158, 2018. DOI: http://doi.org/10.6008/CBPC2179-6858.2018.006.0016 


\section{INTRODUÇÃO}

O território brasileiro é dividido em cinco grandes regiões, de acordo com a divisão definida pelo IBGE (Instituto Brasileiro de Geografia e Estatística), que passou a constar nos mapas em 1970. Para definir os estados de cada região, foram usados critérios ligados ao conjunto de condições naturais que eles têm em comum - clima, relevo, vegetação e hidrografia - à posição geográfica que ocupam e aos aspectos humanos que envolvem as atividades econômicas e o modo de vida da população.

A região Norte é a maior das regiões brasileiras sendo formada por sete estados: Acre, Amapá, Amazonas, Pará, Rondônia, Roraima e Tocantins. A região tem 15.865 .678 habitantes (censo de 2010). Embora seja a maior das cinco regiões, é a segunda menos populosa e a menos povoada (que tem menos habitantes por quilômetro quadrado) do país, a qual se explica pela rica área coberta pela selva, que por ser muito densa, dificulta a ocupação humana. Dessa forma, seus habitantes se concentram nas capitais da região as atividades econômicas e o modo de vida da população.

O Norte do Brasil, é caracterizado por ser uma região com temperaturas bastante elevadas, por conta da sua localização, que fica na linha do equador e faz com que apresente baixas altitudes. A Região também pode ser considerada a mais chuvosa do país, principalmente no período de dezembro a maio. Para Amorim et al. (2010), o clima é um importante condicionante ambiental, que apresenta alterações cíclicas, inesperadas e danosas que afetam o homem e o meio social de forma geral. Assim, o clima também favorece a manifestação de determinados agravos à saúde, tendo seus elementos (temperatura do ar, umidade relativa do ar e precipitação pluviométrica) interferência no bem-estar dos indivíduos.

A asma é uma das doenças respiratórias crônicas mais comuns que afeta de 1 a 18\% da população, havendo variação desse índice para diferentes regiões e países. O Brasil é o oitavo País em prevalência de asma ficando em torno de $10 \%$ da população geral. A variação regional na ocorrência é provavelmente multifatorial e decorrente de genética, exposições perinatais, dieta, obesidade, tabagismo, poluentes intra e extradomiciliar, estresse, infeç̧ões microbianas e parasitárias (GINA, 2017). Preocupados com a qualidade de vida da população urbana (e, também, ambiental), os geógrafos têm cada vez mais se interessados em estudos sobre o clima das cidades e suas interferências no cotidiano da população. Assim, de acordo com Souza et al. (2003):

Poluição do ar, ilha de calor, inundações no espaço urbano, dentre outras formas, assumem destaque nos climas urbanos, refletindo, com isso, peculiaridades do clima da cidade. A relação entre as condições atmosféricas e as doenças respiratórias exemplifica a importância de trabalhos de Climatologia Geográfica e Médica e Geografia da Saúde e Médica, objetivando o planejamento de ações em prol da melhoria da qualidade de vida humana.

A relação existente entre os impactos adversos das condições climáticas na saúde não apresenta uma associação simples, uma vez que a interação entre a exposição a um ou mais fatores de risco e o desenvolvimento de uma doença não é reconhecida facilmente, pois se presume que a relação se dê também a partir de comportamentos sociais comuns, como o tipo de alimentação (GOMES et al., 2013). A asma é uma doença crônica, que se torna de suma importância, tendo um tratamento eficaz para que se mantenha o seu 
controle, de forma que se permite ter uma melhora na qualidade de vida do paciente, mantendo suas atividades de vida diária e função pulmonar normais, bem como prevenir as exacerbações da doença.

Dentre esses fatores, destacam-se a presença de poluentes no ar atmosférico, tanto externo quanto interno, as condições meteorológicas e a velocidade dos ventos, podem aumentar a duração da exposição aos poluentes e impedir sua dissipação (CASTRO, 2005). Entre as variáveis climáticas, a velocidade dos ventos e a umidade relativa do ar têm sido as variáveis mais importantes no aumento de incidência de exacerbações de asma quando em interação com a poluição atmosférica (ANG et al., 2007).

Desta forma, observar as variáveis relacionadas à Asma em determinados meses do ano é necessário, por conta dos danos à saúde humana. Assim, se faz imprescindível a identificação de uma periodicidade para prover elementos para pesquisa de fatores ambientais que possam responder de forma preventiva. Este trabalho teve por objetivo captar associações significativas entre internações por Asma e variáveis meteorológicas em municípios localizados na Região Norte do Brasil.

\section{MATERIAIS E MÉTODOS}

\section{Área de estudo}

O presente estudo utilizou o Norte do Brasil, utilizando seis municípios do estado do Pará, sendo estes: Altamira, Belém, Conceição do Araguaia, Itaituba, Marabá e Óbidos (figura 1). Trabalhou-se com dados mensais de precipitação pluviométrica, umidade relativa do ar, temperatura máxima e temperatura mínima disponibilizada pelo Banco de Dados Meteorológicos para Ensino e Pesquisa (BDMEP) do Instituto Nacional de Meteorologia (INMET). Os registros de internações por asma, segundo o local de residência, foram disponibilizados pelo Banco de Dados do Sistema Único de Saúde (DATASUS) do Ministério da Saúde, no período de 2000 a 2016.

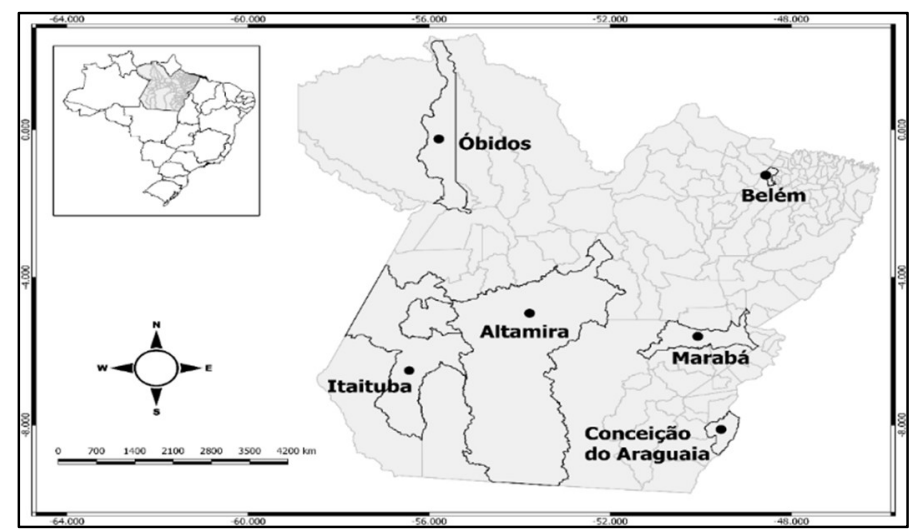

Figura 1: Mapa de localização.

A metodologia utilizada para captar uma associação significativa entre as internações e as variáveis meteorológicas, foi o modelo marginal de equações de estimação generalizadas (GEE), no qual foi empregado com o intuito de obter estimativas confiáveis para as variáveis climáticas e o número de internações por asma levando em conta uma estrutura de correlação que visa a melhorar a eficiência dos estimadores sem perder a consistência dos mesmos. Através deste modelo, podem-se estimar coeficientes de regressão com $5 \%$ de 
significância e erros padrões.

Zeger et al. (1986) propôs as equações de estimação generalizadas, como um método necessário para especificar claramente uma estrutura dos parâmetros do modelo de regressão, pois necessita apenas da especificação do primeiro e do segundo momento da função de densidade marginal, soluciona o problema da independência dos dados quando há necessidade de se trabalhar com dados correlacionados.

A ideia é introduzir uma matriz $R(\alpha)$ simétrica e de dimensão ti, que satisfaça as condições de uma matriz de correlação em que, $\alpha$ é um vetor de dimensão sx1, que caracteriza completamente a matriz $R(\alpha)$; sendo assim, obtêm a matriz de variância e covariância da variável aleatória se a verdadeira correlação entre as observações (correlacionadas) da variável for dada por $\mathrm{R}(\alpha)$.

Permitindo em particular, sob suposição de independência que para cada unidade amostral i seja similar a função escore do modelo de quase verossimilhança, onde esta função requer poucas suposições da variável dependente, pode-se então, definir um modelo linear generalizado para cada instante de tempo acrescentando uma função que faz a ligação entre a parte aleatória e a parte sistemática: nit = g ( $\mu \mathrm{it}$ ), em que $\eta$ it $=x^{\prime}$ it $\beta$ é o preditor linear, $\beta=(\beta 1, \beta 2, \ldots, \beta p)^{\prime}$ é o vetor de parâmetros desconhecidos e de interesse e $g(\mu i t)$ é a função de ligação. Utilizou-se a estrutura para a matriz de correlação do tipo simétrica ou permutável. Na qual, esta matriz deve ser usada quando se assume um modelo de efeitos aleatórios com intercepto aleatório para cada variável, como exemplificado em Lair e Ware.

Para o estudo em questão, considerou-se a distribuição de probabilidade Poisson, em que nit = $\ln (\mu \mathrm{it})$ $=\beta 0+\beta 1 X$, cuja interpretação da exponencial do parâmetro estimado representa o risco relativo. A definição do risco relativo é dada pela razão entre as probabilidades de sucesso de dois níveis da variável explicativa. A fórmula do Risco Relativo é: $R R=\pi 1 / \pi 2$. A técnica estatística foi realizada com o auxílio do software estatístico livre R. Utilizando o pacote geepack (Generalized Estimating Equation Package) e a função gee e glm (Fit Generalized Estimating Equations).

\section{DISCUSSÃO TEÓRICA}

A série temporal para o município de Altamira é mostrada na figura 2, onde o maior registro ocorreu no início de 2006 e o menor em 2002. Observa-se também uma diminuição no número de internações a partir de 2015. Duarte et al. (2015) relata uma queda no número de internamentos na Região Norte do Brasil que ainda não possui uma causa estabelecida claramente, mas parece estar associada a diversos fatores.

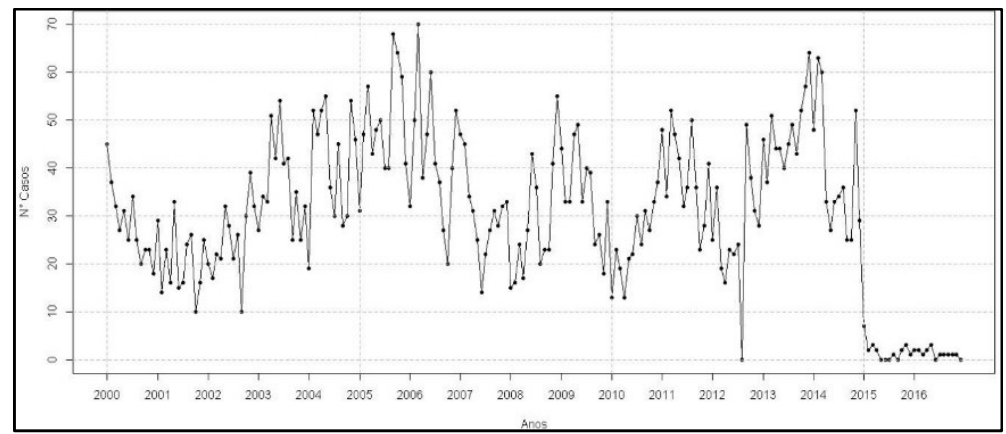

Figura 2: Série temporal do número de casos de Asma na cidade de Altamira (PA), no período 2000 a 2016. 
Observa-se, na figura 3, as variáveis meteorológicas avaliadas neste estudo, onde o máximo de precipitação pluvial foi 574,3mm e o mínimo de 1,6mm, com 186,3mm de média acumulada. Segundo Fischer et al. (1998), a região apresenta período chuvoso de dezembro a março, período menos chuvoso de junho a novembro. É possível notar também que a temperatura apresenta valores médios máximos em setembro $\left(36,7^{\circ} \mathrm{C}\right)$ e média mínima ocorreu em fevereiro $\left(29,8^{\circ} \mathrm{C}\right)$ para temperatura máxima, com pontos discrepantes negativos e positivos em março, julho e agosto. A temperatura mínima apresenta média de $23,3^{\circ} \mathrm{C}$, apresentando outlines em maio, junho e agosto. Por fim, a umidade relativa teve uns percentuais maiores em março $(90,8 \%)$, e menores em outubro $(63,1 \%)$.

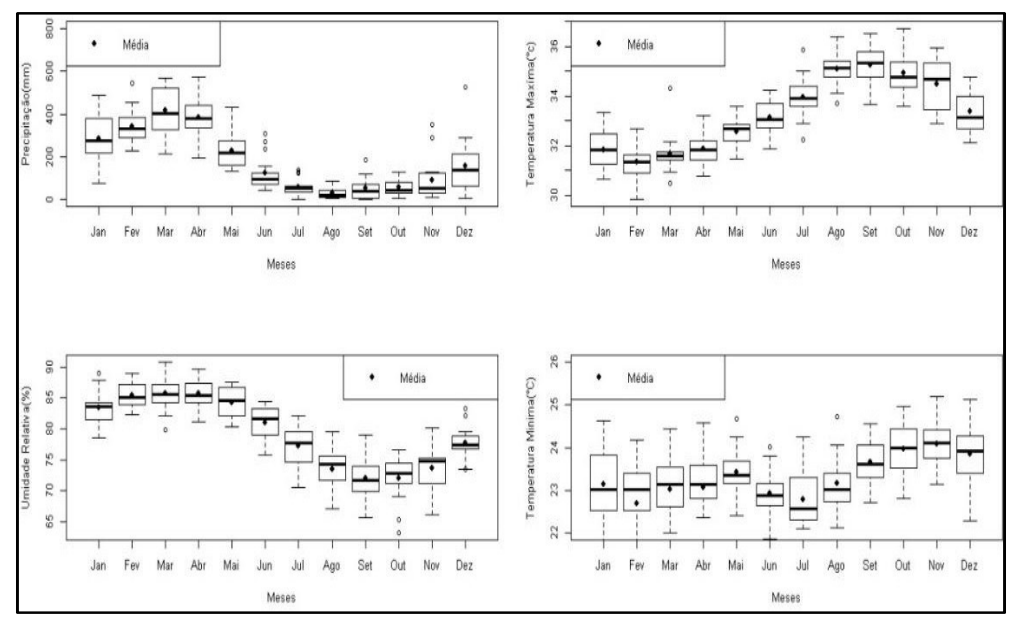

Figura 3: Boxplots das variáveis meteorológicas: Precipitação pluvial (mm), Umidade Relativa do $\operatorname{Ar}(\%)$, Temperatura Mínima $\left({ }^{\circ} \mathrm{C}\right)$ e Temperatura Máxima $\left({ }^{\circ} \mathrm{C}\right)$ respectivamente, em Altamira (PA), no período de 2000 a 2016.

A figura 4 representa a série temporal de internações para a cidade de Belém (PA), onde se nota que de 2000 a 2007 os casos não ultrapassam de 200, mas em 2012, tem-se quase 400 registros (mensais). Os maiores números de casos se manifestam de 2010 a 2013, que ultrapassam os 300 casos por ano. Já na figura 5, o comportamento da variabilidade mensal das variáveis meteorológica, no período de 2000 a 2016.

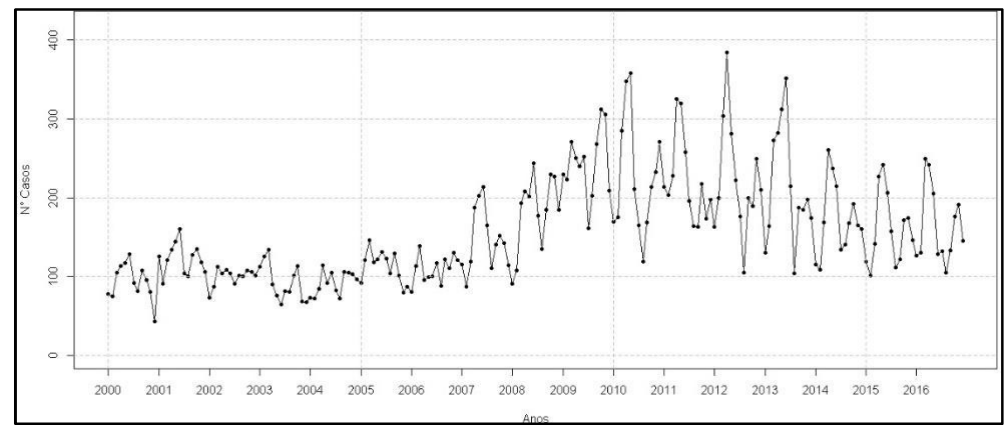

Figura 4: Gráfico de comportamento anual do número de casos de Asma na cidade de Belém (PA).

O período chuvoso na cidade de Belém é em dezembro a maio, sendo abril o mês de transição para o período seco que vai até novembro. O maior volume pluviométrico é nos meses de março $(742,5 \mathrm{~mm})$ e média mínima nos meses de setembro $(26,4 \mathrm{~mm})$. Podendo também observar outlines positivos e negativos ao longe de setes meses (janeiro, fevereiro, julho, agosto, outubro, novembro e dezembro).

A temperatura máxima, com máxima nos meses de novembro $\left(34,62^{\circ} \mathrm{C}\right)$, mínima nos meses de fevereiro $\left(29,75^{\circ} \mathrm{C}\right)$, com outlines positivos e negativos em janeiro, maio, julho, outubro e dezembro. A 
temperatura mínima se mantém quase a mesma, com pouca variação e outlines de janeiro a maio. A umidade relativa, tem valores percentuais mais altos de dezembro a março com transição em abril para os meses menos úmidos os quais ocorrem de maio a novembro, apresentando outlines positivos e negativos em maio, outubro e novembro.

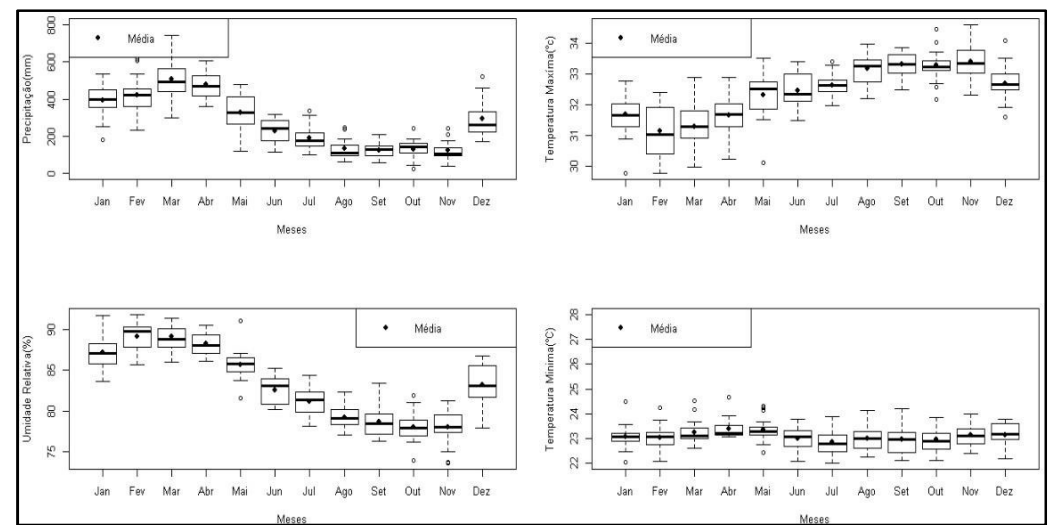

Figura 5: Boxplots das variáveis meteorológicas: Precipitação pluvial (mm), Umidade Relativa do $\operatorname{Ar}(\%)$, Temperatura Máxima $\left({ }^{\circ} \mathrm{C}\right)$ e Temperatura Mínima $\left({ }^{\circ} \mathrm{C}\right)$ respectivamente, Belém (PA) no período de 2000 a 2016.

Mostra-se na figura 6 que, em Conceição do Araguaia (PA), de 2000 a 2005, as internações por asma se mantêm a abaixo de 20 casos, os maiores índices ocorreram de 2006 a 2012, chegando a ultrapassam 30 casos na maioria dos meses. Já na figura 7, o comportamento da variabilidade mensal das variáveis meteorológica, no período de 2000 a 2016.

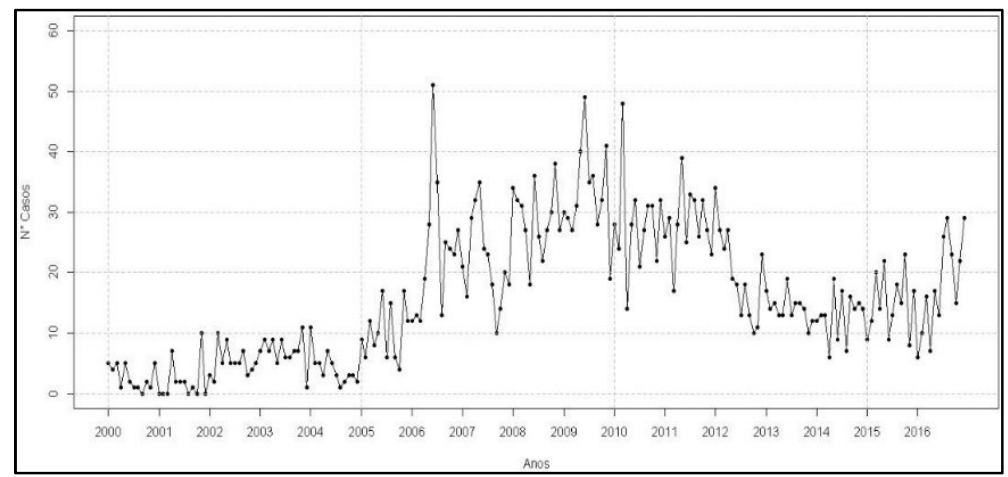

Figura 6: Gráfico de comportamento anual do número de casos de Asma na cidade de Conceição do Araguaia (PA).

O período chuvoso na cidade de Conceição do Araguaia (PA), vai de outubro a março, sendo abril o mês que transita para o período com menos chuvas que vai até agosto, o maior volume pluviométrico é nos meses de março (493mm), podendo também observar outlines positivos nos meses de janeiro a agosto. A temperatura máxima é maior nos meses de agosto $\left(39,17^{\circ} \mathrm{C}\right)$, mínima nos meses de fevereiro, com outlines positivos e negativos em fevereiro, abril, maio, setembro e novembro. A temperatura mínima apresentou valores menores de junho a agosto. Os outros meses têm variação de $0,54^{\circ} \mathrm{C}$, com outlines positivos e negativos nos meses de maio, outubro e novembro. A umidade relativa, os meses de março (94,52\%), e agosto $(49,78 \%)$ com mínima. 


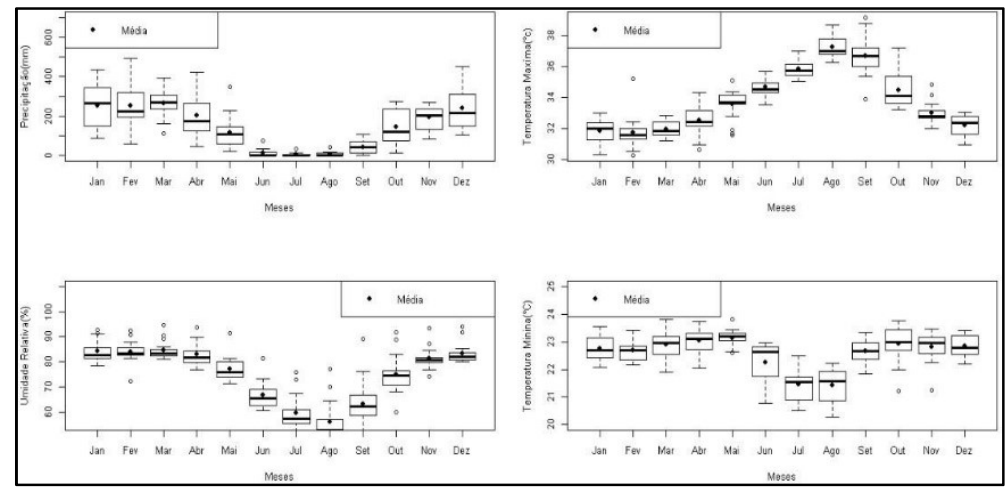

Figura 7: Boxplots das variáveis meteorológicas: Precipitação pluvial (mm), Umidade Relativa do Ar (\%), Temperatura Máxima $\left({ }^{\circ} \mathrm{C}\right)$ e Temperatura Mínima $\left({ }^{\circ} \mathrm{C}\right)$ respectivamente, Conceição do Araguaia (PA), no período de 2000 a 2016.

Observando a figura 8, nota-se que nos anos de 2003 a 2004 em Itaituba (PA), as internações por asma passaram de 150, caindo consideravelmente nos anos seguintes assim como em Altamira como observado por Duarte et al. (2015). Observa-se na figura 9, o comportamento da variabilidade mensal das variáveis meteorológica, no período de 2000 a 2016.

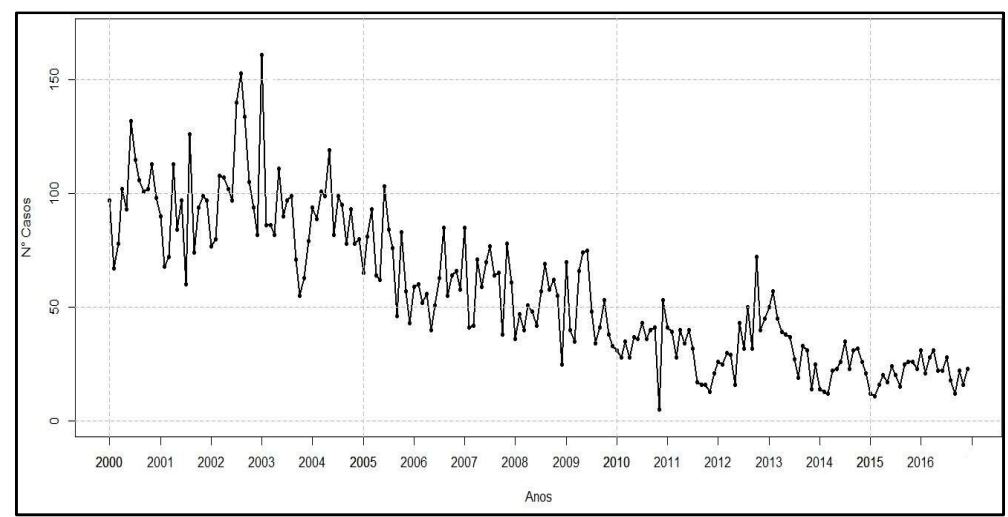

Figura 8: Gráfico de comportamento anual do número de casos de Asma na cidade de Itaituba (PA).

O período chuvoso na cidade de Itaituba é de dezembro a março, onde o mês de transição para o período menos chuvoso é abril, os meses de maio a novembro prevalece um regime menor de chuvas. Existem outlines positivos em janeiro e julho. Em relação a variável de temperatura máxima, os meses onde se encontra maiores valores em setembro $\left(36,58^{\circ} \mathrm{C}\right)$, e os menores no mês de fevereiro $\left(30,60^{\circ} \mathrm{C}\right)$, encontrase outlines nos meses de janeiro, maio e novembro.

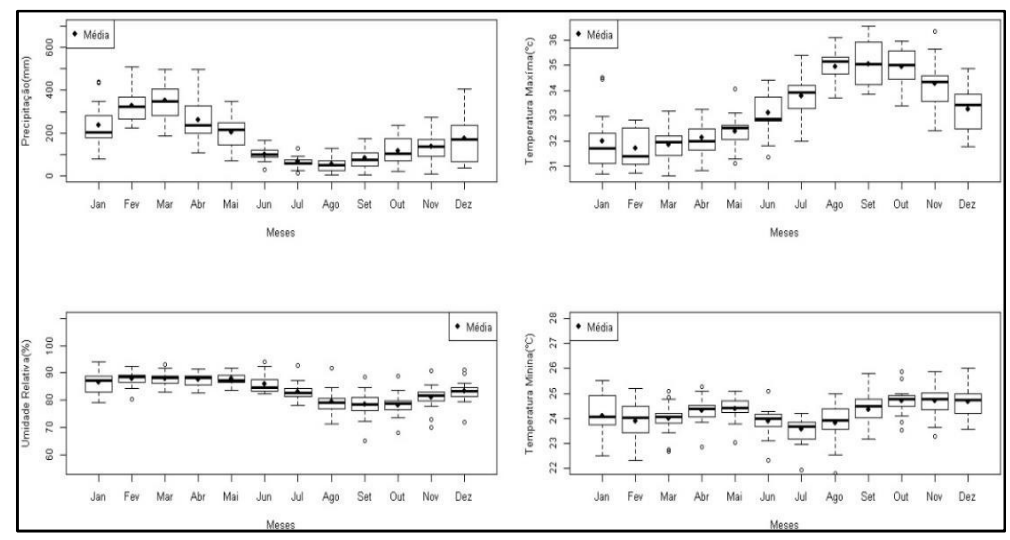

Figura 9: Boxplots das variáveis meteorológicas: Precipitação pluvial (mm), Umidade Relativa do Ar (\%), Temperatura Máxima $\left({ }^{\circ} \mathrm{C}\right)$ e Temperatura Mínima $\left({ }^{\circ} \mathrm{C}\right)$ respectivamente, Itaituba (PA), no período de 2000 a 2016. 
Ressalta-se também que a temperatura mínima não apresenta muita variação, tendo outlines positivos e negativos de março a novembro. A umidade relativa obteve porcentagens máximas em outubro (94,16\%), mínimas em julho $(65,08 \%)$, onde também apresenta outlines positivos e negativos de julho a dezembro. Marabá é mostrada na figura 10 onde observa-se que os maiores registros acontecem de 2000 a 2006, com nenhum somatório mensal acima de 10 casos a partir de 2014. Observa-se na figura 11, o comportamento da variabilidade mensal das variáveis meteorológica em Marabá (PA), no período de 2000 a 2016. O maior volume pluviométrico ocorreu em março $(517 \mathrm{~mm})$ e o menor em agosto $(147,4 \mathrm{~mm})$.

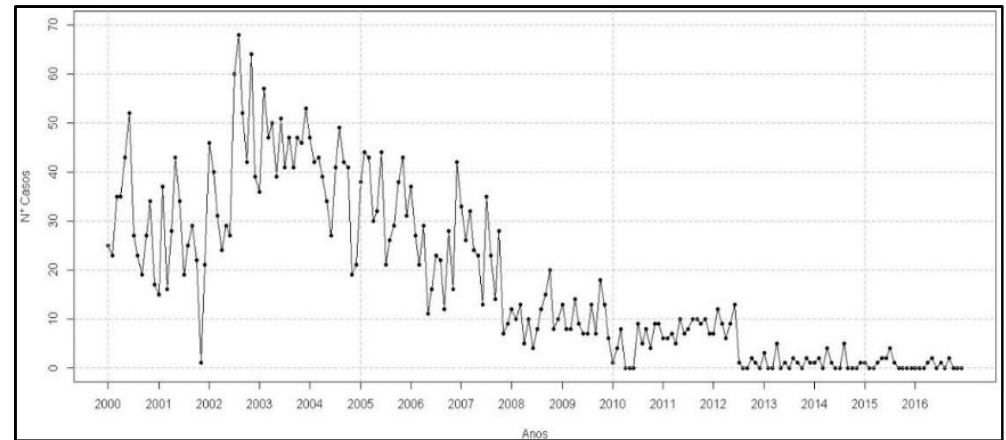

Figura 10: Gráfico de comportamento anual do número de casos de Asma na cidade de Marabá (PA).

A temperatura máxima eleva-se de março a agosto, e diminui a partir dos meses de setembro até dezembro. A temperatura mínima, os menores valores são nos meses de julho $\left(0,55^{\circ} \mathrm{C}\right)$ e maiores nos meses de maio. A umidade relativa se mante com percentual acima de $70 \%$ nos meses de dezembro a abril, onde em maio a junho seguem meses de transição para o período menos úmido de julho a setembro. Todas as variáveis apresentam outlines positivos e negativos.

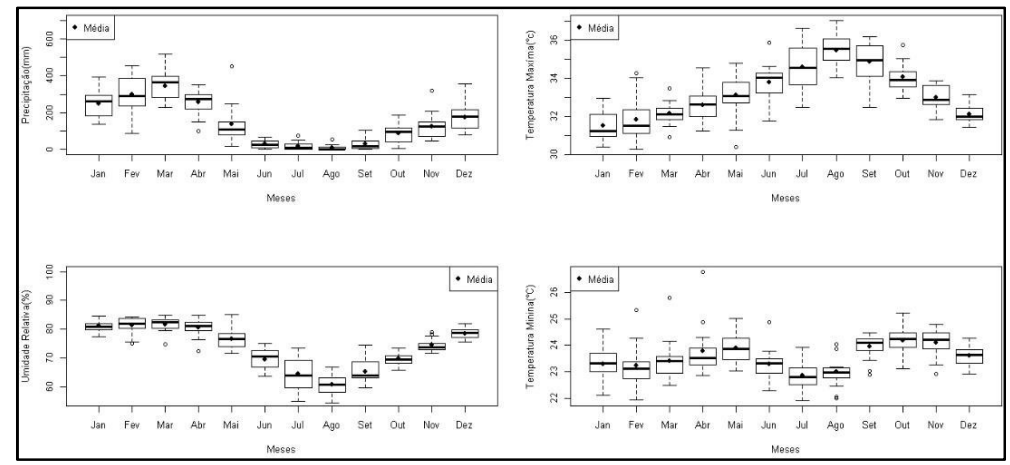

Figura 11: Boxplots das variáveis meteorológicas: Precipitação pluvial (mm), Umidade Relativa do $\operatorname{Ar}(\%)$, Temperatura Máxima $\left({ }^{\circ} \mathrm{C}\right)$ e Temperatura Mínima $\left({ }^{\circ} \mathrm{C}\right)$ respectivamente, Marabá $(\mathrm{PA})$, no período de 2000 a 2016.

O comportamento anual do número de casos na cidade Óbidos (PA), é possível visualizar que a asma no ano de 2008 a 2010 concentra-se os maiores números de casos e em 2011 esse número decresce. Observa-se na figura 13, o comportamento da variabilidade mensal das variáveis meteorológica, no período de 2000 a 2016.

Em Óbidos, os valores de precipitação apresentaram-se máximo em fevereiro $(508,10 \mathrm{~mm})$ e mínimo nos meses de julho e agosto. A temperatura máxima, é elevada nos meses de julho a outubro com máxima de $34,87^{\circ} \mathrm{C}$, em novembro apresenta uma queda na temperatura em abril, com mínima de $29,49^{\circ} \mathrm{C}$ e média de $31,93^{\circ} \mathrm{C}$. Observando a temperatura mínima nota-se que ela não tem muita variação durante todos os 
meses. A umidade relativa é alta nos meses de dezembro a março, em abril começa a diminuir e vai até outubro, umidade máxima de 89,58\%, mínima de 69,08\% e média de 82,07\%. Todas as variáveis apresentam outlines, positivos e negativos.

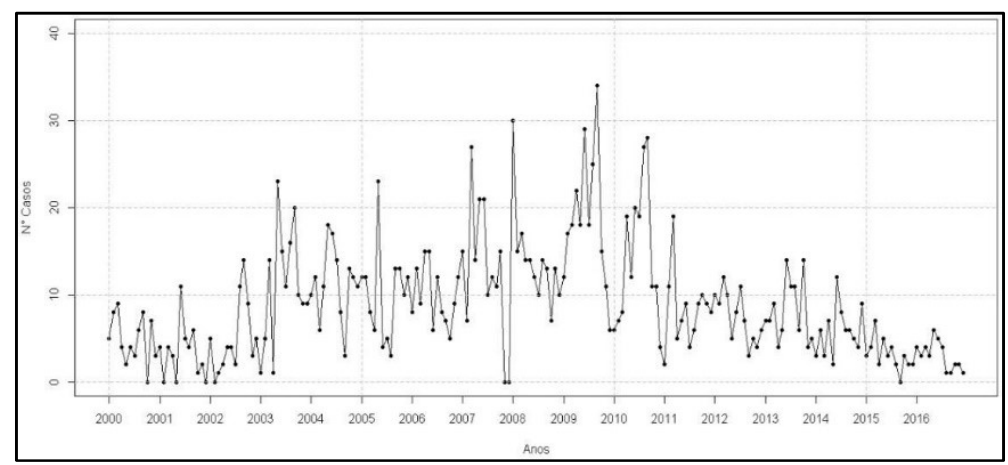

Figura 12: Gráfico de comportamento anual do número de casos de Asma na cidade de Óbidos (PA).

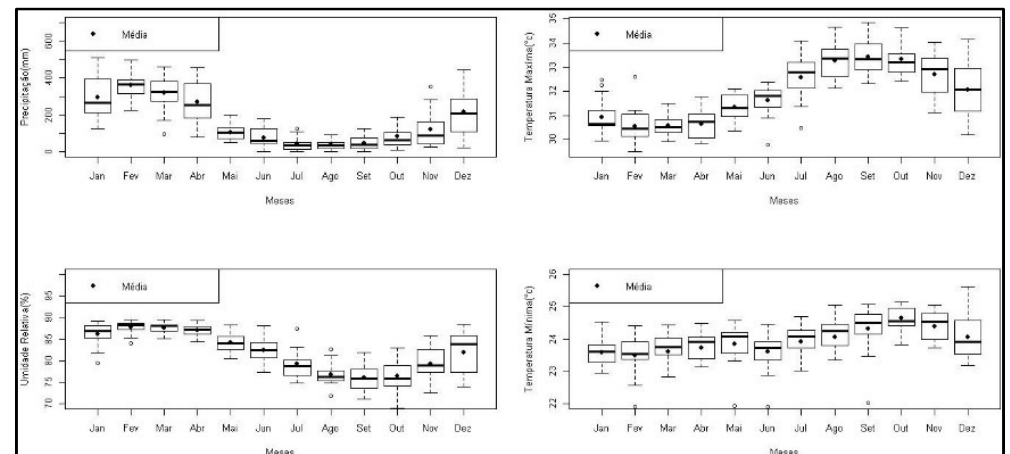

Figura 13: Boxplots das variáveis meteorológicas: Precipitação pluvial (mm), Umidade Relativa do Ar (\%), Temperatura Máxima $\left({ }^{\circ} \mathrm{C}\right)$ e Temperatura Mínima $\left({ }^{\circ} \mathrm{C}\right)$ respectivamente, Óbidos (PA), no período de 2000 a 2016.

O resultado da modelagem via equações de estimação generalizadas é observado na tabela 1, constata-se associação significativa (inversa) entre as internações e a temperatura mínima do ar em Altamira. Logo, se aceita a hipótese que ao ocorrer os menores valores da temperatura mínima, mas contribui para o aumento do número de internações por asma. Este resultado corrobora com o encontrado em Amorim et al. (2018). A temperatura máxima também atua de forma inversa, a precipitação e a umidade de forma direta, no entanto não foram ajustadas significâncias estatísticas. Destaca-se o risco relativo significativo para o aparecimento de crises de asma ocorre quando os valores da temperatura mínima são alterados.

Tabela 1: Modelo Marginal das Equações de Estimação Generalizadas das variáveis estudadas em Altamira (PA), no período de 2000 a 2016.

\begin{tabular}{|l|c|c|c|c|}
\hline & Estimativa & Erro & $\begin{array}{c}\text { Significancia } \\
\boldsymbol{\alpha} \leq \mathbf{0 , 0 5}\end{array}$ & $\begin{array}{c}\text { Risco Relativo } \\
\text { (\%) }\end{array}$ \\
\hline Precipitação & 0,000444 & 0,000238 & NS & 0,00 \\
\hline Temperatura Máxima & $-0,0322$ & 0,0258 & NS & 0,00 \\
\hline Temperatura Mínima & $-0,1058$ & 0,0446 & S & 0,90 \\
\hline Umidade Relativa & 0,00271 & 0,00692 & NS & 0,00 \\
\hline
\end{tabular}

Legenda: NS= Não significativo; $S=$ Significativo.

A partir do resultado da modelagem via equações de estimação generalizadas, observam-se na tabela 2 associações significativas entre as internações com a Temperatura mínima e a Precipitação em Belém. Os valores menos elevados da temperatura do ar e a ocorrência de precipitação contribuem para o aumento do 
número de internações por Asma. O risco relativo sinaliza que é quando ocorre alteração da temperatura mínima do ar que gera o maior risco de ocorrer crises de asma.

Tabela 2: Modelo Marginal das Equações de Estimação Generalizadas, das variáveis estudadas em Belém (PA), no período de 2000 a 2016.

\begin{tabular}{|l|c|c|c|c|}
\hline & Estimativa & Erro & $\begin{array}{c}\text { Significancia } \\
\boldsymbol{\alpha} \leq \mathbf{0 , 0 5}\end{array}$ & $\begin{array}{c}\text { Risco Relativo } \\
\text { (\%) }\end{array}$ \\
\hline Precipitação & 0,000444 & 0,000189 & $\mathbf{S}$ & 1,0 \\
\hline Temperatura Máxima & 0,0127 & 0,0301 & NS & 0,00 \\
\hline Temperatura Mínima & 0,281 & 0,0525 & S & 1,3 \\
\hline Umidade Relativa & 0,00945 & 0,00663 & NS & 0,00 \\
\hline
\end{tabular}

Legenda: NS= Não significativo; $S=$ Significativo.

Para Conceição do Araguaia, o resultado da modelagem via equações de estimação generalizadas é observado na tabela 3, é possível observar associações significativas entre as internações e a Temperatura mínima e com a Umidade relativa. A alteração na temperatura mínima e na umidade relativa contribuem para o aumento do número de internações por asma. O risco relativo sinaliza que é a alteração da temperatura mínima do ar que gera o maior risco de ocorrer crises de asma.

Tabela 3: Modelo Marginal das Equações de Estimação Generalizadas das variáveis estudadas em Conceição do Araguaia (PA), no período de 2000 a 2016.

\begin{tabular}{|l|c|c|c|c|}
\hline & Estimativa & Erro & $\begin{array}{c}\text { Significancia } \\
\boldsymbol{\alpha} \leq \mathbf{0 , 0 5}\end{array}$ & $\begin{array}{c}\text { Risco Relativo } \\
\text { (\%) }\end{array}$ \\
\hline Precipitação & $-0,000292$ & 0,000397 & NS & 0,00 \\
\hline Temperatura Máxima & 0,0147 & 0,0216 & NS & 0,00 \\
\hline Temperatura Mínima & 0,536 & 0,0893 & S & 1,70 \\
\hline Umidade Relativa & $-0,0127$ & 0,0036 & S & 1,00 \\
\hline
\end{tabular}

Legenda: NS= Não significativo; $\mathrm{S}=$ Significativo.

O resultado da modelagem via equações de estimação generalizadas para Itaituba é observado na tabela 4, que mostra associação significativa entre as internações e a Temperatura mínima e com a Umidade relativa. Os valores menos elevados da temperatura do ar e a elevada umidade contribuem para o aumento do número de internações por asma. A relação entre as internações com a precipitação e a temperatura mínima ocorre de forma inversa. O risco relativo sinaliza que é a alteração da umidade relativa que gera o maior risco de aparecimento de crises de asma.

Tabela 4: Modelo Marginal das Equações de Estimação Generalizadas das variáveis estudadas em Itaituba (PA), no período de 2000 a 2016.

\begin{tabular}{|l|c|c|c|c|}
\hline & Estimativa & Erro & $\begin{array}{c}\text { Significancia } \\
\boldsymbol{\alpha} \leq \mathbf{0 , 0 5}\end{array}$ & $\begin{array}{c}\text { Risco Relativo } \\
\text { (\%) }\end{array}$ \\
\hline Precipitação & $-0,000531$ & 0,000327 & NS & 0,00 \\
\hline Temperatura Máxima & 0,00705 & 0,02566 & NS & 0,00 \\
\hline Temperatura Mínima & $-0,2558$ & 0,0433 & S & 0,80 \\
\hline Umidade Relativa & 0,04696 & 0,00625 & S & 1,10 \\
\hline
\end{tabular}

Legenda: NS=Não significativo; S=Significativo.

Para Marabá o resultado da modelagem via equações de estimação generalizadas é observado na tabela 5, constata-se associação significativa entre as internações e a temperatura mínima. Os valores da temperatura mínima contribuem para o aumento do número de internações por asma. 0 risco relativo 
sinaliza que é quando ocorre alteração da temperatura mínima do ar que gera o aparecimento das crises de asma.

Tabela 5: Modelo Marginal das Equações de Estimação Generalizadas das variáveis estudadas em Marabá (PA), no período de 2000 a 2016.

\begin{tabular}{|l|c|c|c|c|}
\hline & Estimativa & Erro & $\begin{array}{c}\text { Significancia } \\
\boldsymbol{\alpha} \leq \mathbf{0 , 0 5}\end{array}$ & $\begin{array}{c}\text { Risco Relativo } \\
\text { (\%) }\end{array}$ \\
\hline Precipitação & $-7,75 \mathrm{E}-05$ & $4,92 \mathrm{E}-04$ & $\mathrm{NS}$ & 0,00 \\
\hline Temperatura Máxima & 0,0234 & 0,0409 & $\mathrm{NS}$ & 0,00 \\
\hline Temperatura Mínima & 0,2357 & 0,0838 & $\mathrm{~S}$ & 1,30 \\
\hline Umidade Relativa & $-0,00329$ & 0,0079 & $\mathrm{NS}$ & 0,00 \\
\hline
\end{tabular}

NS= Não significativo; S= Significativo.

Para Óbidos o resultado da modelagem via equações de estimação generalizadas é observado na tabela 6, não constam associações significativas entre as internações e as variáveis meteorológicas. Logo, pode-se afirmar que as condições meteorológicas em Óbidos não ofereceram risco para o aparecimento de crises de asma no período estudado.

Tabela 6: Modelo Marginal das Equações de Estimação Generalizadas das variáveis estudadas em Óbidos (PA), no período de 2000 a 2016.

\begin{tabular}{|l|c|c|c|c|}
\hline & Estimativa & Erro & $\begin{array}{c}\text { Significancia } \\
\boldsymbol{\alpha} \leq \mathbf{0 , 0 5}\end{array}$ & $\begin{array}{c}\text { Risco Relativo } \\
\text { (\%) }\end{array}$ \\
\hline Precipitação & $-0,0001$ & 0,0001 & NS & 0,00 \\
\hline Temperatura Máxima & 0,0471 & 0,0473 & NS & 0,00 \\
\hline Temperatura Mínima & $-0,0358$ & 0,0696 & NS & 0,00 \\
\hline Umidade Relativa & $-0,0105$ & 0,0109 & NS & 0,00 \\
\hline
\end{tabular}

Legenda: NS= Não significativo; S= Significativo.

Observa-se que somente em Conceição do Araguaia há um aumento no número de casos, e é lá que o modelo aponta o maior risco relativo. Dentre todas as cidades analisadas, $1,70 \%$ que pode estar relacionado com o clima local. Beasley et al. (2015) afirma que um dos fatores de risco para a asma é a condição ambiental. No oeste do estado, Gomes et al. (2015) detecta aumento na temperatura. De acordo com McMichael et al. (2006), mudanças nos parâmetros meteorológicos podem afetar em doenças alérgicas, como a asma.

Gomes et al. (2013) utiliza o modelo marginal das equações de estimação generalizadas para associar fatores meteorológicos com doenças respiratórias na Região Nordeste do Brasil onde o modelo não capta associações com a temperatura do ar, somente detecta quando se é utilizada a sensação térmica dificuldade que não foi encontrada na Região do Oeste do Pará, haja vista que somente Óbidos não captou associações significativas. Carvalho et al. (2016) mostra que a temperatura média e a umidade relativa do ar têm influenciado os casos acometidos de pneumonia na cidade de Campina Grande (PB), resultado que corrobora com esse estudo em todas as cidades, exceto Óbidos. De acordo com Murara (2013) e Santos et al. (2017), a umidade relativa do ar atua de forma inversa nos internamentos por doenças respiratórias, e neste estudo está associação também é observada. 


\section{CONCLUSÕES}

Em todas as cidades analisadas, exceto em Óbidos, o modelo estatístico constatou associações significativas diretas ou inversas entre as variáveis e as internações, mostrando que provavelmente o aumento do número de internações por asma, no período de 2000 a 2016, sofreu influência do comportamento das variáveis meteorológicas.

O modelo utilizado no trabalho levou em consideração apenas fatores climáticos, é preciso destacar que o corpo humano é um sistema complexo e individual, e que existem diversos outros fatores que interferem na saúde, como alimentação, tabagismo, sexo, faixa etária os quais não foram avaliados. Ademais, para traçar o comportamento de uma doença, é necessário também considerar variáveis aleatórias como, por exemplo, fatores sociodemográficos. Ainda assim, observa-se relevante a verificação das influências ambientais, pois condições de meteorológicas são detectores de uma parcela influenciadora importante para que haja ocorrência de internações por asma.

\section{REFERÊNCIAS}

AMORIM, J. R. G.; OLIVEIRA, A. M.; NEVES, D.; OLIVEIRA, G. $P$.. Associação entre variáveis ambientais e doenças respiratórias (asma e bronquite) em crianças na cidade Macapá-AP no período de 2008 a 2012. Revista Internacional de Direito Ambiental e Políticas Públicas, Macapá, n.5, p.141-153, 2013.

ANG, H. P.; DALE, M. M.; RITTER, J. M.; FLOWER, R. J.. Rang \& Dale Farmacologia. 6 ed. Rio de Janeiro: Elsevier, 2007.

BEASLEY, R.; SEMPRINI, A.; MITCHELL, E. A.. Risk factors for asthma: is prevention possible?. The Lancet, v.386, n.9998, p.1075-1085, 2015.

CARABALLO, L.; CADAVIA, A.; MENDOZA, J.. Prevalence of asthma in a tropical city of Colombia. Annals of Allergy, Asthma \& Immunology, v.68, p.525-529, 1992.

CARVALHO, E. K. M.; DANTAS, R. T.; CARVALHO, J. R. M.. Análise da influência entre as variáveis meteorológicas e doenças respiratórias na cidade de Campina Grande, PB (analysis of influence ratio between the variable weather and respiratory diseases in Campina Grande, PB). Revista Brasileira de Climatologia, v.18, 2016.

CASTRO, H. A.. O pulmão e o ambiente: os poluentes do ar e seus efeitos no aparelho respiratório. Jornal Brasileiro de Pneumologia, v.27, n.1, p.3-9, 2001.

DUARTE, I. K.; VIEIRA, R. P. V.; GRAUDENZ, G. S.. Análise das tendências das internações hospitalares por asma no Brasil de 1998 a 2010. Brazilian Journal of Allergy and Immunology, n.1, v.3, 2015.
FISCHER, G. B.. Relação entre a incidência de crises asmáticas e as alterações do clima. Jornal Brasileiro de Pneumologia, v.10, n.1, p.75, 1984.

GOMES, A. C. D. S.; SILVA, A. R. S.; COUTINHO, M. D. L.; COSTA, M. S.; SANTOS, T. S. S.. Modelagem de internações por doenças respiratórias em idosos pela sensação térmica no município de Natal-RN. Ciência e Natura, n.35, v.33, p.4245, 2013.

MCMICHAEL, A. J.; WOODRUFF, R. E.; HALES, S.. Climate change and human health: present and future risks. The Lancet, v.367, n.9513, p.859-869, 2006.

MURARA, P. G.; MENDONÇA, M.; BONETTI, C.. O clima e as doenças circulatórias e respiratórias em Florianópolis. Hygeia, Florianópolis, v.9, n.19, 2013.

SANTOS, D. A. S.; AZEVEDO, P. V.; OLINDA, R. A.; SANTOS, A. C.; SOUZA, A.; SETTE, D. M; SOUZA, P. M.. A relação das variáveis climáticas na prevalência de infecção respiratória aguda em crianças menores de dois anos em RondonópolisMT, Brasil. Ciência e Saúde Coletiva, Rio de Janeiro, v.2, n.11, 2017.

SOUZA, C. G.; SANT'ANNA NETO, J. L.. Ritmo climático e doenças respiratórias: interações e paradoxos. Revista Brasileira de Climatologia, 2008.

ZEGER, S. L.; LIANG, K. Y.. Longitudinal data analysis for discrete and continuos outcmos. Biometrics, v.42, n.1, p.121-130, 1986.

A CBPC - Companhia Brasileira de Produção Científica (CNPJ: 11.221.422/0001-03) detém os direitos materiais desta publicação. Os direitos referem-se à publicação do trabalho em qualquer parte do mundo, incluindo os direitos às renovações, expansões e disseminações da contribuição, bem como outros direitos subsidiários. Todos os trabalhos publicados eletronicamente poderão posteriormente ser publicados em coletâneas impressas sob coordenação da Sustenere Publishing, da Companhia Brasileira de Produção Científica e seus parceiros autorizados. Os (as) autores (as) preservam os direitos autorais, mas não têm permissão para a publicação da contribuição em outro meio, impresso ou digital, em português ou em tradução. 